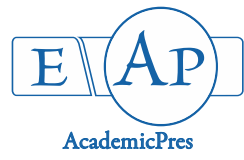

\title{
Impact of Climatic Factors on Radial Growth in Walnut (Juglans regia L.)
}

\author{
Sina COSMULESCU ${ }^{1 *}$, Mariana BÎRSANU IONESCU², \\ Constantin NETOIU ${ }^{3}$ \\ ${ }^{1}$ University of Craiova, Horticulture Faculty, 13 A.I. Cuza Street, 200585 Craiova, \\ Romania; sinacosmulescu@hotmail.com (*correspondingauthor) \\ ${ }^{2}$ University of Craiova, Horticulture Faculty, Doctoral School of Plant and Animal Resources Engineering, 13 A.I. Cuza Street, 200585 Craiova, \\ Romania; mary.yonescu@yahoo.com \\ ${ }^{3}$ INCDS "Marin Dracea" Craiova, 24 George Enescu Street, Craiova, Romania; c_netoiu@yahoo.com
}

\begin{abstract}
Walnut is a species of high vigour, with relatively slow growth, and the size of trees grows with each year of growth. Accumulation of wood biomass, and respectively, productivity, is a resultant synthesis of physiological processes and interaction of trees with environmental factors. The authors have assessed growth characteristics of genotypes standing on their own roots in the sands area of Oltenia (Romania). In terms of tree height, it ranged from $8.53 \mathrm{~m}$ to $18.00 \mathrm{~m}$, while trunk circumference varied between $40 \mathrm{~cm}$ and $229 \mathrm{~cm}$, in genotypes with ages between the 16 and 44 years. Environmental factors, by influencing cambium tissue activity, cell differentiation processes, cell walls growth processes, are inducing particular characteristics of annual rings, in terms of size. The average value of growth ring was $7.09 \mathrm{~mm}$, with a minimum of $3.53 \mathrm{~mm}$, a maximum of $13.94 \mathrm{~mm}$ and variation coefficient of $40.20 \%$. The obtained results show that climatic and edaphic factors of the culture area are influencing the trees growth and development and indicate a good adaptability of genotypes to these conditions.
\end{abstract}

Keywords: climatic factor; radial growth; walnut

\section{Introduction}

Juglans regia L. requires special climatic conditions for growth and fructification. Walnut is a high vigour species, but its growth is relatively slow, and the size of trees is increasing with each year of growth. Accumulation of wood biomass, and respectively, productivity, is a resulting synthesis of physiological processes and interaction of trees with environmental factors. Accumulation of wood biomass and productivity, respectively, is a resulting synthesis of physiological processes and interaction of trees with environmental factors. Size and characteristics of annual growth rings are the result of genotype interaction with the culture medium. Environmental factors influence the walnut growth and development (Botu et al., 2010; Cosmulescu et al., 2010; Bîrsanu Ionescu and Cosmulescu, 2017). Knowing the structure of walnut wood is necessary for setting-up and interpreting models of relationships between the variation of environmental factors and radial trees growth, expressed through the annual ring width, or through its other features (Fritts, 1976). Owens (1995) has shown that climatic conditions, at a certain level, during the vegetation season are affecting fruit production. In analysing the relationships between nut crop yields and annual increment, Winter et al. (2009) found a significantly positive correlation between walnut crop of the current year and ring width of the previous year. Friedrichs et al. (2006) believes that elevation is more important for growth to walnut variables than exposure and inclination. Because growth rings are an integral element of all growth elements, dendrological studies allow the reconstruction of the history of tree growth with an annual resolution. Winter et al. (2009) were illustrates the influence of site conditions and management practices on radial growth of walnut. The radial growth series thus provides a unique perspective on how trees react - directly or indirectly - to a wide variety of climatic factors (Carrer and Urbinati, 2006).

The objectives of this study were to evaluate the characteristics of the growth factors of walnut genotypes and to determine to what extent the age and environmental factors influence the circumference of the trunk and the size of the annual rings, and to what extent genotypes are adapted to environmental conditions. 


\section{Materials and Methods}

\section{Material}

In this paper the walnut genotypes (22) were studied from the Bechet sites $\left(43^{\circ} 47^{\prime} \mathrm{N} / 23^{\circ} 57^{\prime} \mathrm{E}\right)$, Oltenia region (Romania). Oltenia is located in the south-west of Romania, north of the lower Danube River, crossed by the $45^{\circ} \mathrm{N}$ parallel. Bechet is located in the southern part of the region $\left(43^{\circ} 47^{\prime} \mathrm{N} / 23^{\circ} 57^{\prime} \mathrm{E}\right)$, where the average temperature is $11^{\circ} \mathrm{C}$ and the annual average rainfall is $500 \mathrm{~mm}$. Bechet's altitudes is $23 \mathrm{~m}$ in the meadow (near the Danube) and $40 \mathrm{~m}$ (in the sandy area).

\section{Method}

The plant and trunk height were measured with the Wertex 4 device. In order to determine the trunk diameter, the circumference of the trunk was measured at $40 \mathrm{~cm}$ from the ground using a tape measure and was calculated using the formula $\mathrm{L}=2 \prod r$. In order to work out each series of data on radial growth, a number of 22 trees were selected, from which the growth samples were extracted using the Pressler drill at $1.30 \mathrm{~m}$ height from the ground, in the same direction. From each tree, two samples were extracted, avoiding sampling in areas with reaction or compression wood, or wood containing flaws in structure and shape. The collected samples were kept and carried in special plastic tubes provided with holes to ensure their slowly drying. They have undergone a natural drying process, avoiding mould. Subsequently, they were mounted on a wooden stand, sectioned on a flat surface to highlight the structure of the wood, namely the growth rings. Using the Motic binocular stereomicroscope, equipped with a micrometric ladder, W10X/23 lens, the number of annual growth rings and the width of each ring were determined for each analysed genotype. Climatic data used were monthly average rainfall and monthly average temperatures at Bechet meteorological station. The data were statistically processed and correlated, in calculating the adjustment curve and the growth indices.

\section{Results and Discussion}

All the trees under study come from the seed and are found in the semi-cultivated flora. Table 1 shows the age and growth characteristics of genotypes of the three populations analyzed. Walnut trees in Bechet population are aged between 9 years (B19) and 44 years (B29). Age of trees was an important feature in selection, and it also used in other studies (Cosmulescu et al., 2012; Cosmulescu, 2013). Akca and Ozongun (2004) have studied walnut genotypes aged between 20 and 120 years. Average age of trees studied by Winter et al. (2009) is 107 years, the oldest being 291 years in forests, in plantations the average age is 54 years, and the maximum age is 69 years. In terms of tree height, it varied between $8.53 \mathrm{~m} \mathrm{(B43)} \mathrm{and} 18.00 \mathrm{~m}$ (B29). In genotypes analysed by Akca and Ozongun (2004) in Turkey, the tree height ranged from $9 \mathrm{~m}$ to $20 \mathrm{~m}$. Most often, studies on growth processes refer to the accumulation of wood in cross-section. In Bechet population, trunk circumference varied between $40 \mathrm{~cm}(\mathrm{~B} 43)$ and $229 \mathrm{~cm}$
(B29), in genotypes aged 16 years, and 44 years, respectively. B29 genotype is the oldest tree of Bechet population (age 44). In addition, the reported results show that there are also trees of the same age but with a different trunk diameter, respectively B1, B15 and B24, which at 15 years after planting have $23.89 \mathrm{~cm}, 45.86 \mathrm{~cm}$ and $51.27 \mathrm{~cm}$, respectively. The obtained results show that climatic and edaphic factors of the culture area are influencing the trees growth and development and indicate a good adaptability of genotypes to these conditions. Variation limits for trunk circumference of walnut trees analysed in Turkey by Akca and Ozongun (2004) were between 0.80-2.80 m. Arzani et al. (2008) reported genotypes in Taft region of Iran, a trunk circumference between 68 and $520 \mathrm{~cm}$, suggesting the high adaptability of walnuts to pedo-climatic conditions in the region. The smallest trunk circumference, reported by Akca et al. (2015) in Turkey was $66 \mathrm{~cm}$, higher than the inferior limit found in genotypes in Bechet population; and the highest trunk circumference was $185 \mathrm{~cm}$, smaller than the one of Bechet population genotypes $(229 \mathrm{~cm})$. In order to emphasize the existing correlation between trunk age and diameter, correlation was used (Fig. 1). Correlation coefficient had a value of 0.685 and the regression equation $(y=1,0665 x+15,425)$ indicates that under the environmental conditions in the sands area, in genotypes studied, at an increase of one unit of parameter age (1 year), the trunk diameter increases on average by $1.06 \mathrm{~mm}$. Winter et al. (2009) suggesting that the different values of annual growth ring width of walnuts located in different regions and altitudes can be explained by climatic events. To determine to what extent the climatic conditions are influencing radial growth, the method of picking up growth samples and measuring the width of annual rings was used. The results on radial growth variability within genotype and within population are shown in Table 2. Analysing genotypes of Bechet population, the largest width of annual ring growth was recorded in B19 genotype $(19.5 \mathrm{~mm})$ in 2010, while the lowest $(1 \mathrm{~mm})$ was recorded in genotypes B41 (2014), B10 (2009, 2014) B22 (2006), B3 (2014), B5 (2014). The low radial growth in 2014 was mainly due to very low rainfall from July to August, which had values lower by $6.69 \mathrm{~mm}$ and $24.79 \mathrm{~mm}$, respectively, compared to the average of 1961-2017 period. Negative influence also had the very high temperatures recorded in August. The mean value of growth ring in Bechet population is $7.09 \mathrm{~mm}$, with a minimum of $3.53 \mathrm{~mm}$ (B22), a maximum of 13.94 (B19), and variation coefficient of $40.20 \%$. The highest variation coefficient of annual growth values was calculated in B10 genotype (91.71\%), while the lowest (11.81\%) in B15 genotype. Winter et al. (2009) reported in South Kyrgyzstan an average annual increase in walnut plantations of $2.5 \mathrm{~mm} /$ year over the period 1960-2005, much higher than in forest walnuts $(1.7 \mathrm{~mm} /$ year $)$, where man does not intervene. There are large differences between years within the same genotype and among genotypes within the same population, which supports the influence of environmental factors on growth. Environmental factors, by influencing the activity of cambium tissue, cell differentiation processes, cell walls growth, are inducing particular characteristics of annual rings, in terms of size, density etc. 
Table 1. Characteristics of growth elements in analysed genotypes

\begin{tabular}{ccccc}
\hline Genotype & Age $($ year $)$ & Tree height $(\mathrm{m})$ & Trunk height $(\mathrm{m})$ & Trunk diameter $(\mathrm{cm})$ \\
\hline B1 & 15 & 9.2 & 1.1 & 23.89 \\
B3 & 27 & 14 & 1.26 & 58.92 \\
B5 & 32 & 13 & 1.82 & 52.55 \\
B6 & 25 & 13.5 & 1.8 & 50.96 \\
B7 & 21 & 9.8 & 1.9 & 35.03 \\
B8 & 26 & 11.1 & 1.8 & 32.99 \\
B9 & 22 & 10.4 & 1.2 & 32.80 \\
B10 & 28 & 10.5 & 1.25 & 33.76 \\
B11 & 13 & 10.5 & 2.5 & 45,86 \\
B15 & 15 & 15.5 & 2.1 & 40.45 \\
B16 & 24 & 10.1 & 1.6 & 26.75 \\
B19 & 9 & 11.7 & 39.81 \\
B22 & 35 & 14 & 1,4 & 51.27 \\
B24 & 15 & 11.6 & 2.5 & 34.71 \\
B28 & 23 & 10.9 & 1.3 & 72.93 \\
B29 & 44 & 18 & 2.4 & 22.93 \\
B32 & 13 & 9.2 & 1.3 & 39.49 \\
B33 & 18 & 9.2 & 3.5 & 57.96 \\
B36 & 38 & 13.3 & 1.6 & 60.83 \\
B41 & 37 & 11.4 & 2.13 & 25.48 \\
B42 & 30 & 15.3 & 1.52 & 12.74 \\
B43 & 16 & 8.53 & $1.82 \pm 0.57$ & $40.92 \pm 14.56$ \\
Mean \pm SD & & $11.85 \pm 2.44$ & 35.60 \\
\hline CV\% & & 20.59 & & \\
\hline & & & & \\
\hline
\end{tabular}

Dendro-chronological series in walnuts come from the ecosystem of the sands area on the left side of Jiu River (Oltenia, Romania); the evolution of this ecosystem developed under the strong impact of anthropic factor. Dendro-chronological series (Fig. 2) cover a 37-year period (1981-2018). The shape of the average radial growth curve (Fig. 2) is described by logarithmic equation $y=-3.854 \ln (x)$ +16.437 whose correlation coefficient has recorded the highest value $\left(\mathrm{r}=0.93 ; \mathrm{R}^{2}=0.8625\right)$ as compared to the other equations tested. Esper et al. (2001) have described the shape of the average radial growth curve using the exponential equation. Chronological series have been widely used in dendro-climatology for the reconstruction of climatic variability over the centuries (Schweingruber 1983, 1996; Stokes and Smiley, 1968). The correlation strength or quality of these chronologies is changing depending on the living environment of trees from which the samples were taken over and depending on one period or another (Fritts, 1976; Cook and Kairiukstis, 1990). Chronologies from two sites located in the same place do not have the same reconstitute competence and the same timeline for the late $19^{\text {th }}$ century and early $20^{\text {th }}$ century is supported by Esper $e t$ al. (2001), not even for consecutive years (Schweingruber $e t$ al., 1991). The growth indices were calculated as the ratio between the annual growth ring value and the value of adjustment curve described by the logarithmic equation, and it is found that (Fig. 3), largely, the average radial growth and the sum of annual rainfall and, respectively, the vegetation season (April to September) have the same evolution. The shape of average radial growth curve is typical for an ecosystem lacking intensive competition processes, with noteworthy period of 1988-1991 and 20082015, when there is a significant reduction in auxological processes and a growth recovery over 1992-1994, 19962003, and 2005-2008, with negative characteristics years: $1991,1995,2012$, and 2014, known in the literature as dry years. By calculating Spearman correlations, a correlation coefficient of 0.28 (p-level $=0.085807$ ) was obtained between annual growth indices and annual average rainfall, and 0.26 (p-level $=0.111345$ ) was obtained between growth indices and average rainfall of the vegetation season (April to September). The results are significant given that the chronological series come from solitary walnut trees, in semi-cultivated flora where the human factor intervenes through irrigation, canopy cutting, fertilizers application etc. Winter et al. (2009) reported a significantly positive correlation between walnut production of the current year and the annual growth ring width of the previous year (0.32), while the annual increases were negatively correlated with September-October temperatures in the previous year, and positively correlated with the temperatures in May of the current year. In southern Kyrgyzstan (Friedrichs et al., 2006) a significantly positive correlation was reported between the width of forest walnut growth rings and the previous summer rainfall (July, August) and previous winter (November, December), while a negative correlation between was found between the width of growth ring sand rainfall during the current spring season (April, May). 
Table 2. Statistical analysis of annual growth rings in genotypes in Bechet populations

\begin{tabular}{|c|c|c|c|c|c|}
\hline Genotype & Mean $(\mathrm{mm})$ & Standard deviation & Minimum & Maximum & $\mathrm{CV} \%$ \\
\hline B11 & 11.95 & 5.07 & 1.5 & 18.5 & 42.45 \\
\hline B28 & 6.34 & 2.38 & 2 & 11 & 37.56 \\
\hline B19 & 13.94 & 3.97 & 8 & 19.5 & 28.49 \\
\hline B7 & 5.12 & 2.38 & 2 & 10.1 & 46.48 \\
\hline B32 & 5.48 & 2.67 & 2.5 & 11 & 48.71 \\
\hline B1 & 9.02 & 2.42 & 5.5 & 13 & 26.78 \\
\hline B 43 & 4.71 & 1.73 & 2 & 7.5 & 36.80 \\
\hline B9 & 5.54 & 3.01 & 1 & 11 & 54.37 \\
\hline B16 & 6.31 & 4.11 & 2 & 17.2 & 65.16 \\
\hline B8 & 7.00 & 2.38 & 1.5 & 11 & 33.99 \\
\hline B 42 & 6.28 & 2.86 & 2 & 13 & 45.48 \\
\hline B33 & 5.20 & 4.23 & 1.3 & 16 & 81.33 \\
\hline B6 & 5.28 & 2.35 & 2 & 12 & 44.54 \\
\hline B29 & 10.70 & 3.98 & 3.5 & 23 & 37.16 \\
\hline B36 & 6.74 & 3.31 & 1.7 & 14 & 49.10 \\
\hline B 41 & 5.68 & 4.13 & 1 & 14.7 & 72.69 \\
\hline B10 & 3.73 & 3.42 & 1 & 14 & 91.71 \\
\hline B24 & 8.08 & 5.23 & 1.3 & 17.4 & 64.67 \\
\hline B15 & 12.67 & 1.50 & 10.5 & 15.5 & 11.81 \\
\hline B22 & 3.53 & 2.11 & 1 & 9 & 59.96 \\
\hline B3 & 6.81 & 4.58 & 1.1 & 15.5 & 67.29 \\
\hline B5 & 5.80 & 3.09 & 1 & 13.5 & 53.37 \\
\hline Bechet population & 7.09 & 2.85 & 3.53 & 13.94 & 40.20 \\
\hline
\end{tabular}

Table 3. Spearman correlations between growth indices and sum of annual rainfall, namely over the vegetation season April-September

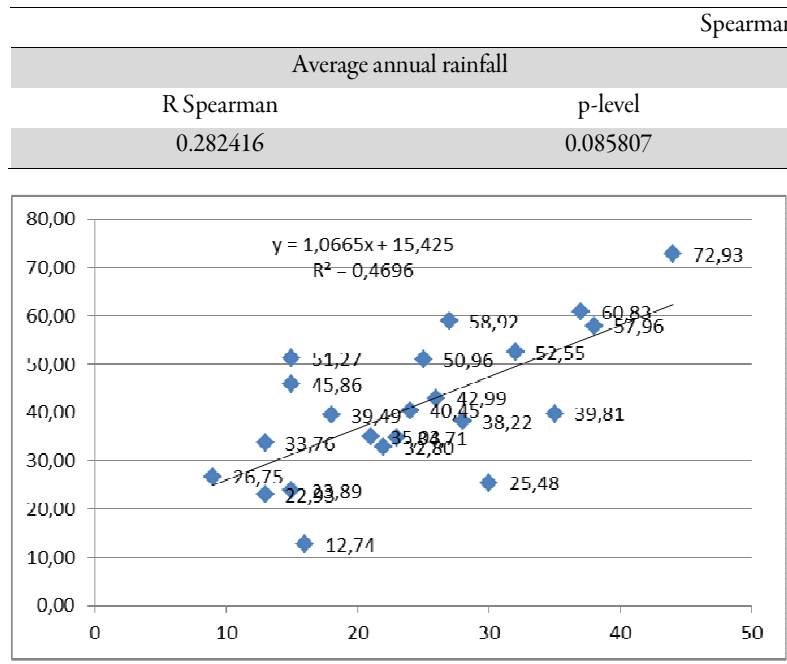

Fig. 1. Correlation between trees age and trunk diameter

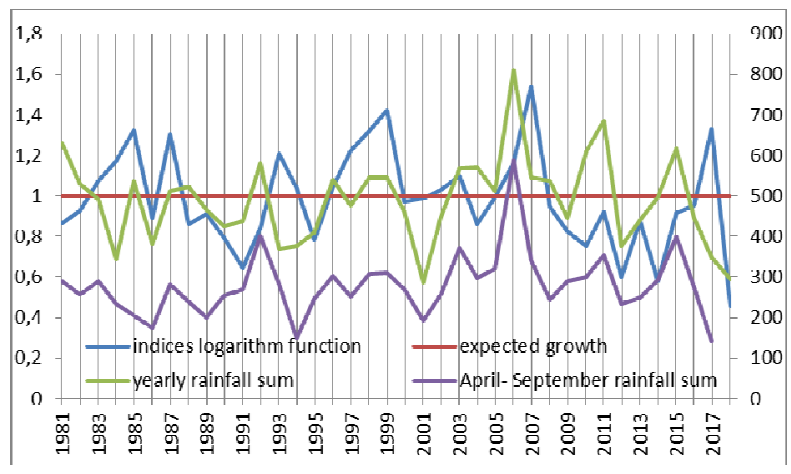

Fig. 3. Correlation coefficients of the radial growth of walnut genotypes under the influence of monthly average rainfall and rainfall over the vegetation season

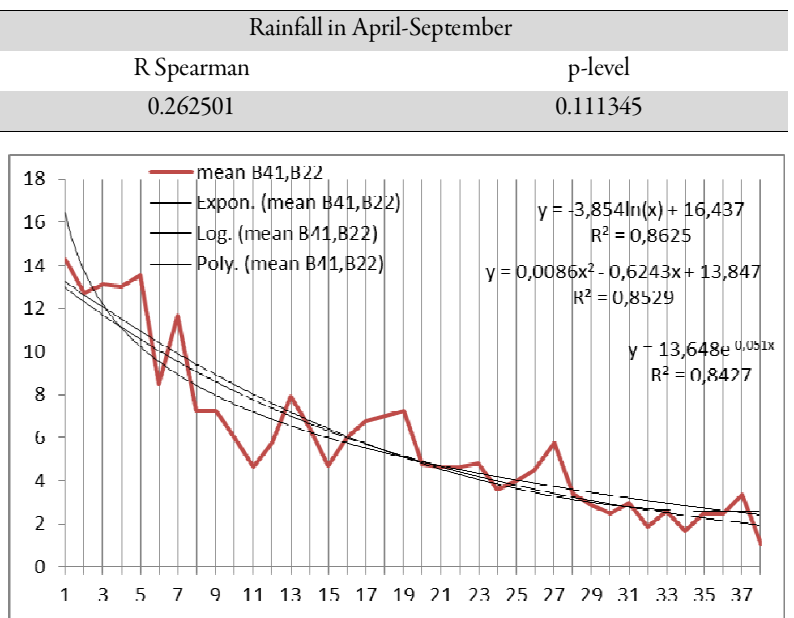

Fig. 2. Mean increase series in dendro-chronological area

\section{Conclusions}

In conclusion, the method of collecting growth samples and measuring of annual rings width, commonly used in dendrometry studies, can be successfully used to analyse the relationships between radial growth in walnut and climatic factors and to determine the age of genotypes. This dendroecological study provides information on radial growth in walnut (Juglans regia L.) and the relationships established between this parameter and climatic factors.

\section{Conflicts of interest}

The authors declare that there are no conflicts of interest related to this article. 


\section{References}

Akca Y, Bilgen Y, Ercisli S (2015). Selection of superior persian walnut (Juglans regia L.) from seedling origin in Turkey. ACTA Scientiarum Polonorum Horticulture 14(3):103-114.

Akca Y, Ozongun S (2004). Selection of late leafing, late flowering, laterally fruitful walnut (Juglans regia L.) types in Turkey. New Zealand Journal ofCropand Horticultural Science 32(4):337-342.

Arzani K, Mansouri-Ardakan H, Vezvae A, Roozban MR (2008). Morphological variation among Persian walnut (Juglans regia) genotypes from central Iran. New Zealand Journal of Crop and Horticultural Science 36(3):159-168.

Bîrsanu Ionescu M, Cosmulescu S (2017). Effect of climatic conditions on flowering of walnut genotypes in Romania. Jurnal of Nuts 8(2):161167.

Botu M, Tudor M, Botu I, Cosmulescu S, Papachatzis A (2010). Evaluation of walnut cultivars in the conditions of the Oltenia's hill area regarding functioning potential. Analele Universitatii din Craiova 15:94103.

Carrer M, Urbinati C (2006). Long-term change in the sensitivity of treering growth to climate forcing of Larix decidua. New Phytologist 170(4):861-872.

Cook ER, Kairiukstis LA (Eds.) (1990). Methods of dendrochronology. Applications in the environmental science. Kluwer, Dordrecht pp 153162.

Cosmulescu S, Baciu A, Botu M, Achim G (2010). Environmental factors' influence on walnut flowering. Acta Horticulturae 861:83-88.

Cosmulescu S (2013). Phenotypic diversity of walnut (Juglans regia L.) in Romania - opportunity for genetic improvement. South-Western Journal of Horticulture, Biology andEnvironment 4(2):117-126.
Cosmulescu S, Botu M (2012). Walnut biodiversity in south-western Romania resource for perspective cultivars. Pakistan Journal of Botany 44(1):307-311.

Esper J, Neuwirth B, Treydte K (2001). A new parameter to evaluate temporal signal strength of tree ring chronologies. Dendrochronologia 19(1):93-102.

Friedrichs D, Neuwirth B, Gottschling H (2006). Dendroecological analysis of growth anomalies in walnut forests in Southern Kyrgyzstan. TRACE - Tree Rings in Archaelogy. Climatology and Ecology 4:144150.

Fritts HC (1976). Tree Rings and Climate. Academic Press, p 567.

Owens JN (1995). Constraints to seed production: temperature and tropical trees. TreePhysiology 15(7-8):477-490.

Schweingruber FH (1983). Der Jahrring, Standort, Methodik, Zeit und Klimain der Dendrochronologie.

Schweingruber FH, Wehrli U, Aellen-Rumo K, Aellen M (1991). Weiserjahre als Zeiger extremer Standorteinflüsse. Schweizer Zeitschrift für Forstwesen 142:33-52.

Schweingruber FH (1996). Tree rings and environment. Dendroecology. Paul Haupt, Bern.

Stokes MA, Smiley TL (1968). An introduction to tree ring dating. The University of Chicago Press, Chicago.

Winter MB, WolffB, Gottschling H, Cherubini P (2009). The impact of climate on radial growth and nut production of Persian walnut (Juglans regia L.) in Southern Kyrgyzstan. European Journal of Forest Research 128(6):531-537. 